\title{
Hepatic thyroid signaling of heat-stressed late pregnant and early lactating cows
}

\author{
Joachim M Weitzel', Torsten Viergutz', Dirk Albrecht'2, Rupert Bruckmaier ${ }^{3}$, \\ Marion Schmicke ${ }^{4}$, Armin Tuchscherer5, Franziska Koch ${ }^{6}$ and Björn Kuhla ${ }^{6}$ \\ ${ }^{1}$ Institute of Reproductive Biology, Leibniz Institute for Farm Animal Biology (FBN), Dummerstorf, Germany \\ 2Institute of Microbiology, Ernst-Moritz-Arndt-University, Greifswald, Germany \\ 3Veterinary Physiology, Vetsuisse Faculty, University of Bern, Bern, Switzerland \\ ${ }^{4}$ Clinic for Cattle, Endocrinology Laboratory, University of Veterinary Medicine Hannover, Hannover, Germany \\ Institute of Genetics and Biometry, Leibniz Institute for Farm Animal Biology (FBN), Dummerstorf, Germany \\ ${ }^{6}$ Institute of Nutritional Physiology 'Oskar Kellner', Leibniz Institute for Farm Animal Biology (FBN), \\ Dummerstorf, Germany
}

Correspondence should be addressed to B Kuhla

Email

b.kuhla@fbn-dummerstorf. de

\begin{abstract}
During the transition between late gestation and early lactation, dairy cows experience severe metabolic stress due to the high energy and nutrient requirements of the fetus and the mammary gland. Additional thermal stress that occurs with rising temperatures during the ongoing climate change has further adverse implications on energy intake, metabolism and welfare. The thyroid hormone (TH)-mediated cellular signaling has a pivotal role in regulation of body temperature, energy intake and metabolic adaptation to heat. To distinguish between energy intake and heat stress-related effects, Holstein cows were first kept at thermoneutrality at $15^{\circ} \mathrm{C}$ followed by exposure to heat stress (HS) at $28^{\circ} \mathrm{C}$ or pair-feeding (PF) at $15^{\circ} \mathrm{C}$ for 6 days, in late pregnancy and again in early lactation. Herein, we focused on hepatic metabolic changes associated with alterations in the hypothalamic-pituitary-thyroid axis in $\mathrm{HS}$ and PF animals. $\mathrm{T}_{3}$ and $\mathrm{T}_{4}$ levels dropped with HS or PF; however, in HS animals, this decline was more pronounced. Thyroid-stimulating hormone (TSH) levels remain unaffected, while plasma cholesterol concentrations were lower in HS than PF animals. Hepatic marker genes for TH action (THRA, DIO1 and PPARGC1) decreased after HS and were lower compared to PF cows but only post-partum. Proteomics data revealed reduced hepatic amino acid catabolism ante-partum and a shift toward activated beta-oxidation and gluconeogenesis but declined oxidative stress defense post-partum. Thus, liver metabolism of HS and PF cows adapts differently to diminished energy intake both ante-partum and post-partum, and a different TH sensitivity is involved in the regulation of catabolic processes.
\end{abstract}

\section{Key Words}

- thyroid hormone metabolism

thyroid-stimulating hormone

- liver

- dairy cow

- heat stress http://joe.endocrinology-journals.org DOI: 10.1530/JOE-17-0066 Printed in Great Britain

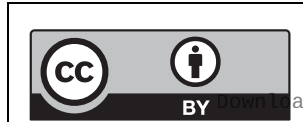

This work is licensed under a Creative Commons Attribution 3.0 Unported License.
Journal of Endocrinology (2017) 234, 129-141 


\section{Introduction}

Thyroid hormone (TH) has a profound influence on normal development, differentiation and metabolism. Genomic actions of THs are mainly mediated and regulated by thyroid hormone receptors (THRs) (Cheng et al. 2010, Cioffi et al. 2013, Davis et al. 2013). THRs bind to $\mathrm{TH}$ response elements, which are located in promoter sequences of target genes but may also be positioned several thousand base pairs up- or downstream of the regulated gene (Cheng et al. 2010, Weitzel \& Iwen 2011). The THRs belong to a group of transcription factors whose gene regulation function is depending on the presence or absence of their particular ligand (i.e. TH). Liganded and un-liganded THRs recruit cofactors which convert chromatin in an open or closed conformation, respectively (Astapova \& Hollenberg 2013). Concentrations of thyroid hormones in the circulation are regulated via the negative feedback loop by the action of thyroid-stimulating hormone (TSH). Beside these regulatory mechanisms, the ligand itself can be modified e.g. via the action of deiodinases (Piehl et al. 2011, Gereben et al. 2015).

The combined action of THR together with its ligand regulates a wide variety of $\mathrm{TH}$ target genes via TH response elements. The primary THR targets include other transcription factors (e.g. the nuclear respiratory factor-1, NRF1) and transcriptional cofactors (e.g. PPAR $\gamma$ coactivator-1 $\alpha$, PPARGC1). These primarily regulated factors serve as intermediate factors, which regulate and orchestrate a second series of TH target genes (Weitzel \& Iwen 2011). This combined action finally regulates numerous TH target genes among those who are responsible for mitochondrial activity and biogenesis (e.g. phosphoenolpyruvate carboxykinase (PEPCK), glycerol-3phosphate dehydrogenase (GPDH) or mitochondrial ATP synthase subunit beta (ATP5B)).

$\mathrm{TH}$ is a profound regulator of body temperature. An excess of TH (hyperthyroidism) is associated with increased body temperature, whereas a TH deficiency (hypothyroidism) is associated with a decrease in body temperature (Mullur et al. 2014). Both statuses are accomplished by accelerated and dampened metabolic activities, respectively. Further, alterations in important thyroid hormone-triggered signal transduction pathways lead to modulations of body temperature. Transgenic mouse models carrying a targeted gene mutation in the THRA or the mitochondrial GPDH genes show impaired thermoregulation (Eto et al. 1999, Warner et al. 2013). Also, reciprocal mechanisms apply. Upon exposure to environmental heat, the affected organism responds with a decline in TH concentrations (Mullur et al. 2014).

In high-producing dairy cows, elevated ambient temperatures during the summer period induce metabolic heat stress, which has adverse effects on milk production, reproductive performance and animal welfare issues, among others. Counterregulatory mechanisms generally include an increased sweating rate, increased water intake and decreased feed intake, all contributing to reduce endogenous heat production (Lamp et al. 2015). However, the ratio of hepatic glucose output to milk lactose output is increased, whereas lipolysis and fat oxidation are not activated in heat-stressed lactating cows despite being in a catabolic state (Wheelock et al. 2010, Lamp et al. 2015). The shift in substrate utilization from fat to glucose has been proposed to diminish endogenous heat production while maintaining hepatic gluconeogenesis for fetus development in late gestation and milk production in early lactation (Koch et al. 2016). However, the molecular mechanisms underlying the shift in substrate utilization during heat stress have not been entirely elucidated so far. It seems likely that the TH system and TH-mediated signaling play a pivotal role in the control of substrate utilization and thus body temperature of heat-stressed cows. In order to distinguish between heat and energy intake-related effects, we analyzed the liver metabolism associated with the hypothalamic-pituitary-thyroid axis in late pregnant and early lactating Holstein cows kept either under heat stress (HS) or pair-fed (PF) conditions at thermoneutrality. We determined circulating endocrine hormones and the hepatic expression levels of known $\mathrm{TH}$ target genes as well as differentially regulated target genes in a holistic proteomics approach. The results of the study show that cows respond to HS by a more severe decline in plasma $\mathrm{T}_{3}$ and $\mathrm{T}_{4}$ but not TSH concentrations compared to PF cows and that early lactating but not late pregnant cows have reduced abundances of thyroid hormone receptor alpha (THRA), iodothyronine deiodinase 1 (DIO1) and PPARGC1, an activated hepatic beta-oxidation and gluconeogenesis and a concomitantly decline in oxidative stress defense enzymes.

\section{Methods}

\section{Animals and sampling}

Fourteen German Holstein dairy cows at the end of the 2nd parity were genotyped for HDP70.1 5'UTR 895 
(Basirico et al. 2011) according to the genotype equally allocated to heat-stressed (HS, $n=7$ ) or pair-feeding (PF, $n=7$ ) group as described earlier (Lamp et al. 2015). The experiment was approved by the Ethic Committee of the State Government Mecklenburg-West Pomerania (Registration No. LALLF M-V/TSD/7221.3-1.1-074/12). All cows were not milked within the 7 weeks prior to the expected calving date. Animals received a total mixed ration twice daily at 07:00 h and 15:00 h. Both groups passed through a 13-day trial once in ante-partum (ap) (HSap and PFap) and post-partum (pp) stage (HSpp and PFpp).

The trial lasted from days 21 to $8( \pm 2.8)$ before and again from days 22 to $35( \pm 1.5)$ after parturition. Animals were halter trained and well adapted to climate chambers with a light cycle ranging from 06:00 to 19:00. The 13-day trial consisted of 6 days of period P1, one day of thermal transition (=day 1 of P2) and 6 further days of P2, each in the ap and pp period.

During period P1, both HS and PF groups were exposed to the same climate conditions $\left(15^{\circ} \mathrm{C}, 63 \pm 1 \%\right.$ relative humidity (RH) resulting in a temperaturehumidity-index (THI) of 60) with ad libitum feeding. On the following transition day, the air temperature was continuously increased to permanent $28^{\circ} \mathrm{C}$ for $\mathrm{HS}$, but maintained at $15^{\circ} \mathrm{C}$ for PF animals (experimental period P2). RH equilibrated within $24 \mathrm{~h}$ to $52 \pm 2 \%$ for HS cows resulting in a $\mathrm{THI}=76$. The THI was calculated according to the guidelines of the National Research Council (NRC 1971): $\quad \mathrm{THI}=\left(1.8 \times \mathrm{AT} \quad\left({ }^{\circ} \mathrm{C}\right)+32\right)-(0.55-0.0055 \times \mathrm{RH}$ $(\%)) \times\left(1.8 \times \mathrm{AT}\left({ }^{\circ} \mathrm{C}\right)-26\right)$. Feed intake was recorded daily. Reduction of daily ad libitum intake of HS cows during P2 was calculated as percentage of the mean daily intake in P1 to provide the same amount of feed to PF cows in P2. Cows had free access to water, which was tempered to $28^{\circ} \mathrm{C}$ for $\mathrm{HS}$ and $15^{\circ} \mathrm{C}$ for PF cows during P2.

Cows were equipped with a jugular catheter (Certofix mono; B-Braun, Melsungen, Germany) to collect daily blood samples into $9 \mathrm{~mL}$-monovettes (Sarstedt, Nümbrecht, Germany) containing EDTA before morning feeding. Blood samples were placed on ice and centrifuged immediately at $1570 \mathrm{~g}$ for $20 \mathrm{~min}$ at $4^{\circ} \mathrm{C}$ to obtain plasma, which was stored at $-80^{\circ} \mathrm{C}$ before analysis.

\section{Plasma hormones and cholesterol}

Total plasma triiodothyronine $\left(\mathrm{T}_{3}\right)$ and thyroxine $\left(\mathrm{T}_{4}\right)$ were measured by radioimmunoassay as described by Vicari and coworkers (2008). Plasma thyroid-stimulating hormone (TSH) concentrations were measured as described previously (Meyerholz et al. 2016) using an in-house ELISA. For the ELISA, an antibody targeted against bovine TSH (anti-bovine TSH, 1:10 pre-diluted, AFP-642482Rb) was obtained from the National Hormone and Peptide Program (NHPP, National Hormone and Peptide Program, NIDDK and Dr Parlow) and was diluted and used at a final dilution of 1:2500. The standard curve ranged from 0.2 to $100 \mathrm{ng} / \mathrm{mL}$ bovine TSH (AFP-8755B, obtained from the NHPP, NIDDK and Dr Parlow) that was dissolved in peptide buffer. The standards, controls and plasma samples (in triplicate) were added to a microtiter plate coated with the antibody, and the plate was then incubated for $24 \mathrm{~h}$ at RT. After washing the plate, biotinlabeled TSH (AFP-8755B, obtained from the NHPP, NIDDK and Dr Parlow) was added to all of the wells and incubated for $3 \mathrm{~h}$. Then, a streptavidin horseradish peroxidase solution (Sigma Aldrich) was added, the substrate (containing tetramethylbenzidine, Sigma Aldrich) was pipetted after washing and the reaction was stopped after 15 min by adding sulfuric acid (2M; Sigma Aldrich). The optical density was obtained at a wavelength of $450 \mathrm{~nm}$, and the concentrations were calculated using Magellan software with the cubic spline modus (Magellan 3.11, Dortmund, Germany). The intra-assay CV was determined by measuring one bovine sample 20 times, and the result was $15.4 \%$. The lowest detection limit of the ELISA was $0.6 \mathrm{ng} / \mathrm{mL}$ which was determined by using the last detectable concentration of a bovine serum sample that was serially diluted. Plasma cholesterol concentrations were analyzed photometrically (Abx Pentra 400, Horiba, Kyoto, Japan) using a cholesterol kit (No. 553-127, MTI Diagnostics, Idstein, Germany).

Liver biopsies were taken before morning feeding at the end of period P1 and on day 7 of P2, both ap and pp. To this end, the skin around the 12th intercostal space was anesthetized with $10 \mathrm{~mL}$ Isocaine $2 \%$ (Serumwerk, Bernburg, Germany), and a sample was taken with a tailormade biopsy needle (Ø $6 \mathrm{~mm}$ ). Biopsies were placed on absorbent paper to soak in blood, and the remaining liver tissues were snap frozen in liquid nitrogen and stored at $-80^{\circ} \mathrm{C}$ until analysis. Due to severe sickness of individual cows, which were excluded from the trial, or due to limited tissue obtained in either P1 or P2, molecular analyses could only be performed on HSap $n=6$, PFap $n=5$, HSpp $n=6$ and PFpp $n=4$ cows.

\section{mRNA preparation and qRT-PCR}

Tissues were mortared under liquid nitrogen, and total RNA was extracted from $50 \mathrm{mg}$ tissue powder with TriFast

Published by Bioscientifica Ltd. 
Reagent (Peqlab, Erlangen, Germany). Concentration and quality of the extracted RNA were measured using a NanoDrop ND-1000 Spectrophotometer (Peqlab Biotechnologie $\mathrm{GmbH}$ ). Ratios of absorbance at 260 and $280 \mathrm{~nm}$ of all preparations were about 2.0. RNA quality was further assessed using an Agilent 2100 Bioanalyzer, yielding RNA integrity numbers (RIN) of 9.1 \pm 0.5 . Firststrand cDNA synthesis (750 ng total RNA) was completed using $2400 \mathrm{U}$ RevertAid Reverse Transcriptase (Thermo Fisher Scientific) and $250 \mathrm{pmol}$ random primers (Metabion International, Planegg/Steinkirchen, Germany). A negative control, without reverse transcriptase, was processed for each sample to detect possible contaminations of genomic DNA or environmental DNA. Aliquots $(1 \mu \mathrm{L})$ of each RT reaction $(1 / 20$ of total) were primed, in each $10 \mu \mathrm{L}$ PCR, using an iQ-SYBR green supermix (Bio-Rad Laboratories) and gene-specific oligonucleotides (final concentration of $0.2 \mu \mathrm{M})$. The sequences of specific bovine primers used are shown in Supplementary Table 2 (see section on supplementary data given at the end of this article). PCR was performed with $3 \mathrm{~min}$ at $94^{\circ} \mathrm{C}$ followed by 40 cycles of $10 \mathrm{~s}$ at $94^{\circ} \mathrm{C} ; 30 \mathrm{~s}$ at $60^{\circ} \mathrm{C} ; 225 \mathrm{~s}$ at $70^{\circ} \mathrm{C}$, which were followed by a single elongation step of $7 \mathrm{~min}$ at $70^{\circ} \mathrm{C}$ using an iCycler (Bio-Rad Laboratories $\mathrm{GmbH}$ ). The specificity of amplification was determined and confirmed by (i) melting curve analysis, (ii) agarose gel electrophoresis and (iii) by sequencing. Each PCR reaction was performed in duplicate, and the amount of transcripts was given as pg per $100 \mathrm{ng}$ total RNA using standard curves for each transcript.

\section{Sample preparation and 2-DE analyses}

Liver tissue powder $(50 \mathrm{mg})$ was homogenized using a teflon pestle in $200 \mu \mathrm{L}$ of $8 \mathrm{M}$ urea, $50 \mathrm{mM}$ Tris, $2 \%$ CHAPS, $40 \mathrm{mM}$ DTT, 0.5\% IPG buffer. After centrifugation $\left(11,000 \mathrm{~g}, 4^{\circ} \mathrm{C}, 20 \mathrm{~min}\right)$, the protein concentration in the supernatant was measured according to the Bradford method using bovine serum albumin (BSA) as standard. Where possible, individual samples were run in technical duplicates for the P1 and P2 period yielding 21 gels for 6 HSap, 19 gels for 5 PFap, 21 gels for 6 HSpp and 14 gels for 4 PFpp cows. A sample of $300 \mu \mathrm{g}$ protein was added to $320 \mu \mathrm{L}$ rehydration buffer (8M urea, $2 \%$ CHAPS, $0.8 \%$ IPG-buffer, $18 \mathrm{mM}$ DTT and a trace of bromophenol blue), mixed and loaded to $18 \mathrm{~cm}$ IPG (pH 3-10; Amersham) as previously described (Schaff et al. 2012). Active rehydration and IEF was performed at $50 \mathrm{~V}$ for $12 \mathrm{~h}$ followed by $500 \mathrm{~V}$ for $1 \mathrm{~h}, 1000 \mathrm{~V}$ for $1 \mathrm{~h}$ and $8000 \mathrm{~V}$ for $4 \mathrm{~h} 20 \mathrm{~min}$ using an Ettan IPGphor3 device (GE Healthcare). IPGs were equilibrated in buffer containing $50 \mathrm{mM}$ Tris ( $\mathrm{pH} 8.8)$, $30 \%$ glycerol, $6 \mathrm{M}$ urea, 2\% SDS, 1\% DTT and then in the same buffer without DTT, but 2.5\% iodoacetamide, each for $15 \mathrm{~min}$. IPGs were transferred to $12.5 \%$ SDS-PAGE gels $(20 \times 20 \times 0.1 \mathrm{~cm})$ and embedded in low melting agarose. The gels were stained overnight in colloidal Rotiblue (Roth, Karlsruhe, Germany), de-stained 3 times in 15\% methanol and 5\% acetic acid and once in distilled water.

\section{Image analysis}

Gels were scanned using an Epson Perfection 1250 scanner and saved as TIFF (8-bit gray scale). The 2-DE image analysis was carried out using Delta2D software version 4.6 (Decodon, Greifswald, Germany; http://www. decodon.com). The 40 gel images from the ap and the 35 gel images from the pp period were separately warped according to the 'all to one' warping strategy. A fusion image was created from all warped images containing all spots from all gels, each for the ap and pp period, respectively. After automatic spot detection on the ap and pp fusion images, spot boundaries were transferred to the original images and were quantified using the gray value of each spot to obtain the spot volume. Each spot volume was normalized to the total spot volume of each gel image $(=100 \%)$ yielding the normalized spot volume in $\%$. Only those spots were identified by mass spectrometry, which differed between the P1 and P2 period of HSpp by $P<0.1$ while remaining unaffected in PFpp cows. Spots differing between the P1 and P2 period of PF cows were not considered. Identified spots are displayed on representative 2D gels in Supplementary Fig. 1.

\section{Mass spectrometry}

Protein identification was performed by a refined method described and compiled previously (Schaff et al. 2012). Briefly, protein spots were punched out using an Ettan spot cutter (Amersham) with a $\varnothing 2 \mathrm{~mm}$ picker head. Spots were transferred into 96-well plates, tryptic digested and subsequently spotted on a MALDI-target. The molecular masses of tryptic digests were measured on a 5800 MALDI TOF/TOF Analyzer (Applied Biosystems). The spectra were recorded in a mass range from 900 to $3700 \mathrm{Da}$ with a focus on $1600 \mathrm{Da}$. For the record of one main spectrum, 30 measuring points per tryptic digest spot were exposed to laser bombardment. At each measuring point, 200 laser shots were set generating 200 sub-spectra, which were http://joe.endocrinology-journals.org DOI: $10.1530 / J O E-17-0066$
(C) 2017 The authors Printed in Great Britain
Published by Bioscientifica Ltd 
subsequently accumulated to one main spectrum. When the autolytical fragments of trypsin with $(\mathrm{M}+\mathrm{H})+m / z$ at 1045.556 and 2211.104 reached a $\mathrm{S} / \mathrm{N}$ of at least 40 , an internal calibration was automatically performed as twopoint calibration. The standard mass deviation was less than $0.15 \mathrm{Da}$. After calibration, the peak lists were created by using the 'peak to mascot' script of the 4000 Series Explorer Software (version 3.5). Selected settings were the following: mass range from 900 to $3800 \mathrm{Da}$, peak density of 15 peaks per $200 \mathrm{Da}$, minimal area of 100 and maximal 60 peaks per spot. The peak list was created for an $\mathrm{S} / \mathrm{N}$ of 10 .

To confirm the results obtained by MALDI-TOF-MS, MALDI-TOF-TOF analysis was performed on the 5800 MALDI TOF/TOF Analyzer (Applied Biosystems). The three strongest peaks of the TOF-spectra were selected automatically and measured. For one main spectrum 25 sub-spectra with 255 shots per sub-spectrum were accumulated using a random search pattern. The internal calibration was automatically performed as one-point calibration with $(\mathrm{M}+\mathrm{H})+m / z$ at 175.119 or with Lys $(\mathrm{M}+\mathrm{H})+m / z$ at 147.107 reached a $\mathrm{S} / \mathrm{N}$ of at least 5 . The peak lists were created for a $\mathrm{S} / \mathrm{N}$ of 7 . Selected settings were the following: mass range from $60 \mathrm{Da}$ to (precursor-20) Da, peak density of 15 peaks per $200 \mathrm{Da}$, minimal area of 100 and maximal 65 peaks per precursor.

For the identification of proteins, a data base search with peptide mass fingerprint (PMF) was performed against NCBInr (National Center for Biotechnology Information, http://www.ncbi.nlm.nih.gov/) database using the Mascot search engine version 2.4.1 (Matrix Science, London, UK). Search parameters were the following: taxonomy: 'all entries'; variable modifications: 'carbamidomethyl $(\mathrm{C})^{\prime}$ and 'oxidation $(\mathrm{M})^{\prime}$; precursor tolerance ' $\pm 50 \mathrm{ppm}$; peptide charge ' $1+$ '; MS/MS fragment tolerance ' $0.5 \mathrm{Da}^{\prime}$; MS/MS tolerance '0.5 Da'; 'monoisotopic'. Mascot criteria for acceptance of protein identifications by PMF were 'number of masses matched', 'number of masses not matched'. A Mascot overall Protein Score greater than 75 fulfilled the $95 \%$ confidence interval (C.I. $\% ; P<0.05)$ and are listed in Supplementary Table 1.

\section{Western blot}

Liver tissue $(30 \mathrm{mg})$ was homogenized in lysis buffer containing $50 \mathrm{mM}$ Tris- $\mathrm{HCl}, 1 \mathrm{mM}$ EDTA, $10 \mathrm{mM} \mathrm{NaF}, 1 \%$ IGPEAL CA-630, 0.1\% Triton X100, 0.5\% deoxycholic acid (DCA) and $0.1 \%$ SDS (pH 7.8). Protein concentrations were determined using the Bradford method. Equal amounts of protein $(25 \mu \mathrm{g})$ were separated by SDS-PAGE. Separated proteins were transferred to a nitrocellulose membrane, stained with Ponceau S, scanned and saved as image file. Membranes were blocked with 3\% BSA in Tris-buffered saline (TBS, pH 7.8) containing $0.1 \%$ Tween 20 (TBST) for $1 \mathrm{~h}$ and then incubated overnight with the following primary antibodies against: ATP synthase subunit beta (ATP5B; sc-166338, Santa Cruz Biotechnology), protein disulfide-isomerase precursor (P4HB; AV48151, SigmaAldrich), regucalcin (RGN; 17947-1-AP; Protein Tech Group). After incubation, membranes were washed in TBST, incubated for $1 \mathrm{~h}$ at room temperature with the corresponding secondary antibody (goat antirabbit IgG HRP, sc-2004, Santa Cruz Biotechnology) and washed again in TBST. Chemiluminescent reagents were applied, and blots were exposed to hyperfilms (GE Healthcare). Hyperfilms were scanned, and bands were quantified using ImageJ (version 1.49). Optical density of immunostained bands was normalized to corresponding Ponceau S-stained lanes.

\section{Statistical analysis}

Due to interindividual variation between HS and PF cows in the P1 period, plasma concentrations of total $\mathrm{T}_{3}$, total $\mathrm{T}_{4}, \mathrm{TSH}$ and cholesterol were baseline corrected to the mean value of the last three days of thermoneutral P1 conditions. Plasma $\mathrm{T}_{3}, \mathrm{~T}_{4}$ and TSH data were analyzed by repeated measurement ANOVA with the MIXED procedure of SAS/STAT software (Version 9.4, SAS Institute Inc., Cary, NC, USA). The ANOVA model contained the fixed factors group (levels: HS, PF), time (challenge day) and the interaction group $\times$ time. Repeated measures on the same animal were taken into account by the REPEATED statement of the MIXED procedure. The block diagonal residual covariance matrix was unstructured for baseline-corrected values $\left(\mathrm{T}_{3}, \mathrm{~T}_{4}\right.$, TSH and cholesterol), whereas it was autoregressive for plasma concentrations of total $\mathrm{T}_{3}$ and total $\mathrm{T}_{4}$. Least-squares means (LSM) and their standard errors (s.E.) were computed for each fixed effect in the models, and all pairwise differences of LSM were tested by the Tukey-Kramer procedure. The SLICE statement of the MIXED procedure was used for performing partitioned analyses of the LSM for the interaction group $\times$ time. For PCR and proteome analyses, differences between periods $\mathrm{P} 1$ and $\mathrm{P} 2$ in the same group were analyzed using the Wilcoxon signed rank sum test included in the UNIVARIATE procedure of Base SAS. Analysis of differences between two groups of the same

Published by Bioscientifica Ltd. 
period and the same productive stage was performed using the exact Wilcoxon-Mann-Whitney test of SAS/ STAT. Data are given as mean \pm S.E. Results were considered as statistical significant at $P<0.05$.

\section{Results}

\section{Thyroid hormones and TSH}

After increasing ambient temperature to $28^{\circ} \mathrm{C}(\mathrm{THI}=76)$, HS dairy cows responded with declining total $\mathrm{T}_{3}$ and total $\mathrm{T}_{4}$ concentrations both in the ap (Fig. $1 \mathrm{~A}$ and $\mathrm{B}$ ) and pp period (Fig. 1D and E). The $\mathrm{T}_{3}$ level dropped from $\sim 2 \mathrm{nmol} / \mathrm{L}$ at thermoneutrality $\left(15^{\circ} \mathrm{C}, \mathrm{THI}=60\right)$ to $\sim 1.2 \mathrm{nmol} / \mathrm{L}$ after challenge (day 7 in $\mathrm{P} 2$ ), whereas $\mathrm{T}_{4}$ levels dropped from $\sim 65 \mathrm{nmol} / \mathrm{L}$ at thermoneutrality to $\sim 35 \mathrm{nmol} / \mathrm{L}$ in ap animals $\left(P_{\text {time }}<0.001\right.$; Supplementary Fig. 2). The $T_{3} / T_{4}$ ratio remained unaffected during treatments (data not shown). Total plasma $\mathrm{T}_{3}$ was $\sim 0.3 \mathrm{nmol} / \mathrm{L}$, and total plasma $\mathrm{T}_{4}$ was $\sim 22 \mathrm{nmol} / \mathrm{L}$ lower in HSpp than HSap animals, both before (P1) and after challenge, while the extent of reduction over time $\left(P_{\text {time }}<0.05\right)$ was comparable in both periods (Fig. 1B and E). Also, pair-fed animals responded by a reduction of $\mathrm{TH}$ levels both in the ap and pp period. However, plasma $T_{3}$ and $\mathrm{T}_{4}$ concentrations declined or tended to decline lesser in PFap compared to HSap cows $\left(\mathrm{T}_{3}: P<0.05\right.$ for days 6 and 7 of $\mathrm{P} 2 ; \mathrm{T}_{4}: P<0.1$ for days 4 and 6 of $\mathrm{P} 2, P<0.05$ for days 3 and 7 of P2; Tukey-Kramer). TSH concentrations remained constant at approximately $1 \mathrm{ng} / \mathrm{mL}$ with no significant alterations over time or between animals, and independent of whether animals were in the ap or pp period (Fig. 1C and F). In the pp period, total $\mathrm{T}_{3}$ and $\mathrm{T}_{4}$ plasma concentrations tended to be lower in HS than PF cows $\left(P_{\text {group }}<0.1\right)$; however, pairwise comparisons revealed no differences after the 7-day challenge period (Fig. 1D and E). Only on days 2 and 3 of P2, total $\mathrm{T}_{4}$ differed between PFpp and HSpp cows (Fig. 1E).

\section{Hepatic intracellular thyroid signaling}

To examine whether the different or the tending different declines in circulating $\mathrm{TH}$ concentrations in $\mathrm{HS}$ and $\mathrm{PF}$ animals affect cellular thyroid signaling, we measured various hepatic marker genes for $\mathrm{T}_{3}$ action. In the ap period, exposure to HS or isocaloric feeding at thermoneutrality did not significantly alter RNA concentrations of THRA, DIO1, NRF1 and PPARGC1 from P1 to P2 (Fig. 2A, C, E and G). Only the NRF1 RNA abundance tended to increase in PF cows relative to ad libitum feeding at thermoneutrality (Fig. 2E).
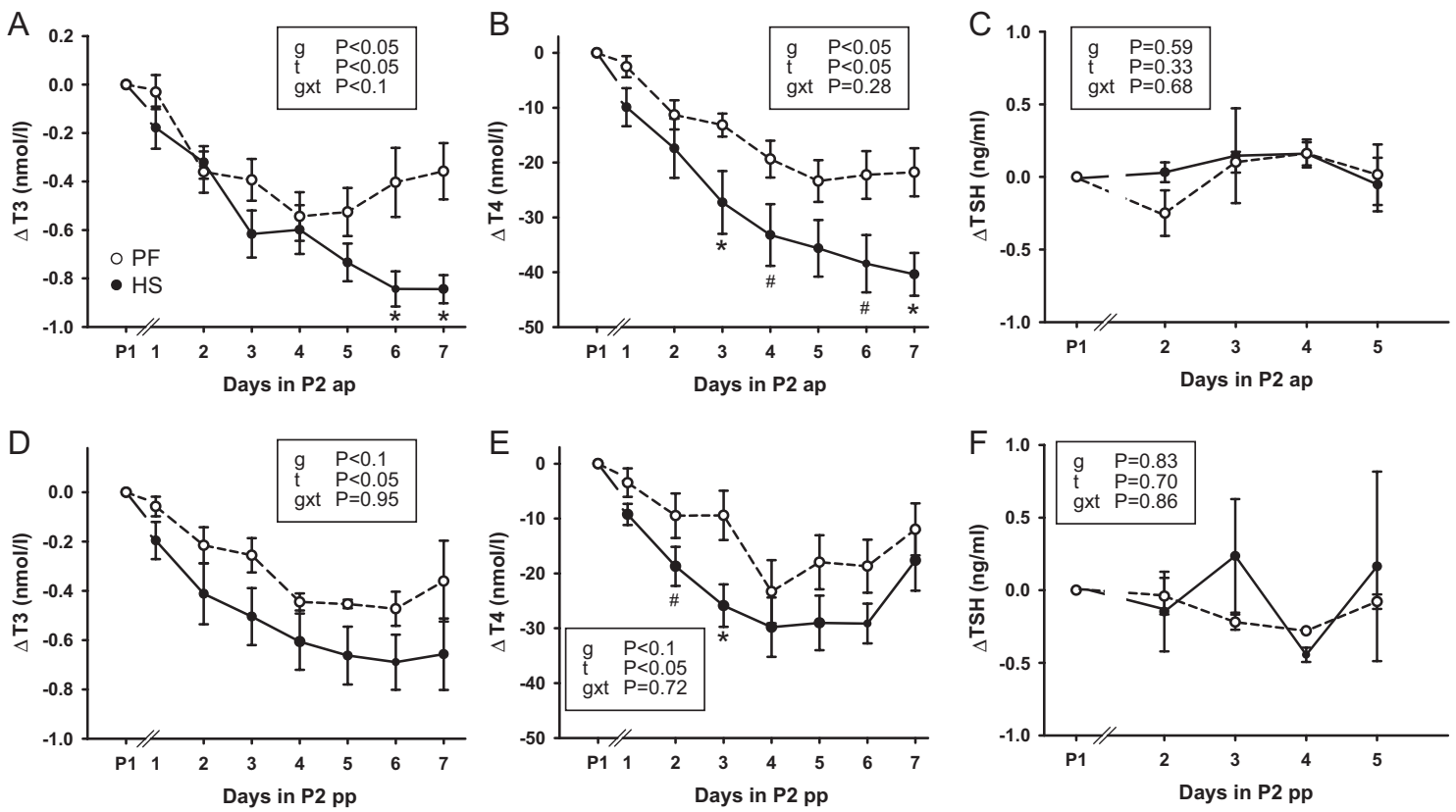

Figure 1

Baseline-corrected plasma concentrations of total $\mathrm{T}_{3}$, total $\mathrm{T}_{4}$ and TSH determined after ad libitum feeding at thermoneutrality in $\mathrm{P} 1$, the transition day (day 1 of P2) and during the 6 subsequent challenge days of period P2 of either heat stress (HS, filled circles) or pair-feeding at thermoneutrality ( $P F$, open circles) in the ante-partum (ap) and post-partum (pp) period, respectively. Data are given as mean \pm s.E.M. $P$ values for the effects between groups $(\mathrm{g})$, over time $(\mathrm{t})$ and their interaction $(\mathrm{g} \times \mathrm{t})$ are presented within graphs. * indicates $P<0.05$ and ${ }^{\#} P<0.1$ for pairwise comparisons between groups. HSap $n=7$, PFap $n=6, \operatorname{HSpp} n=6, \operatorname{PFpp} n=6$.

http://joe.endocrinology-journals.org DOI: $10.1530 / \mathrm{JOE}-17-0066$
(C) 2017 The authors Printed in Great Britain
Published by Bioscientifica Ltd. 
A
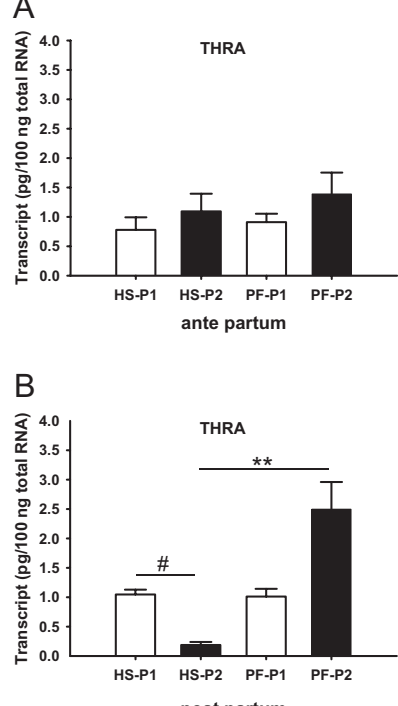

C
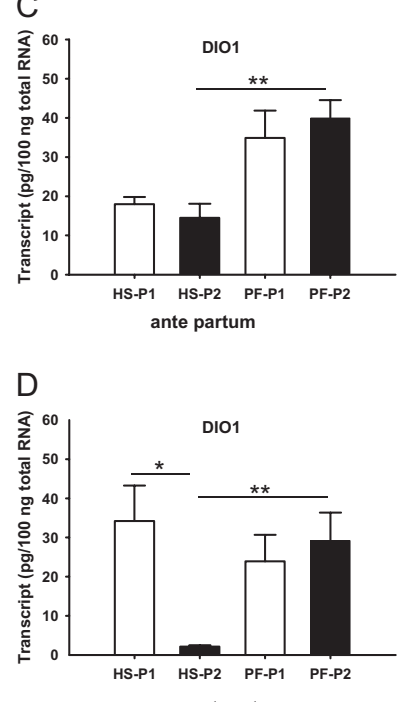

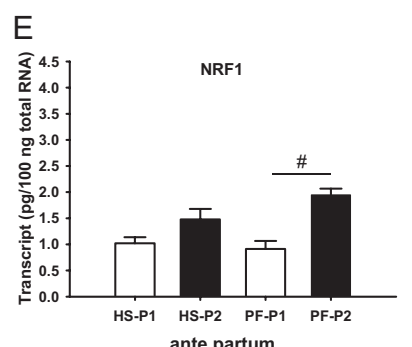

F

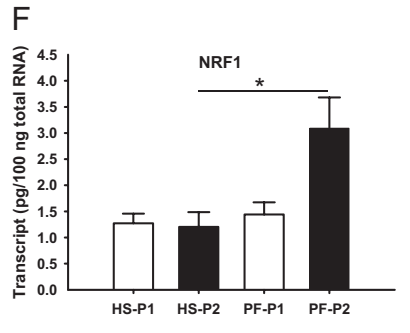

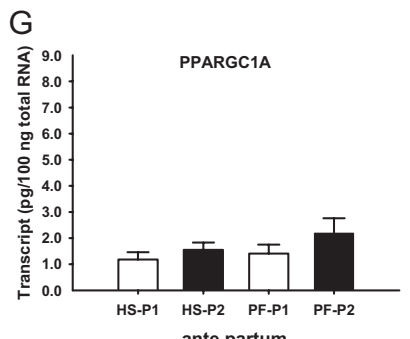

ante partum

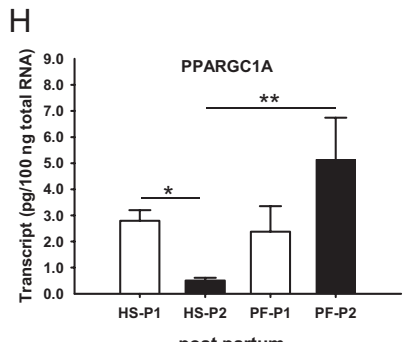

Figure 2

mRNA abundances of (A, B) thyroid hormone receptor alpha (THRA), (C, D) deiodinase 1 (DIO1), (E, F) nuclear respiratory factor 1 (NRF1), and (G, H) peroxisome proliferator-activated receptor gamma coactivator 1-alpha (PPARGC1A) in liver samples obtained after ad libitum feeding at thermoneutrality (P1; open bars) and after heat stress (HS; filled bars) or pair-feeding at thermoneutrality (PF; filled bars) at day 7 in P2, both in the ante-partum and post-partum period, respectively. ** indicates $P<0.01,{ }^{*} P<0.05$, and $\# P<0.1$ ). Data are from HSap $n=6$, PFap $n=5$, HSpp $n=6$,

PFpp $n=4$ and are presented as mean \pm S.E.M.

In addition, DIO1 mRNA abundance differed significantly between PF and HS cows in the P2 state; however, this difference rather arise from the different expression levels in P1 (Fig. 2C). In the pp period, however, transition from thermoneutrality to HS but not to PF reduced gene expression levels for THRA, DIO1 and PPARGC1A $(P<0.05)$ by $82-94 \%$ (Fig. 2B, D and H), However, mRNA abundance of NRF1 was not affected by HS, yet, abundances of NRF1, THRA, DIO1 and PPARGC1A were 2.8-14 times greater in PF compared to HS-challenged animals (Fig. 2B, D, F and H).

\section{Hepatic metabolism}

To elucidate hepatic metabolic processes potentially associated with the different plasma $\mathrm{TH}$ concentrations between HSap and PFap cows and different cellular signal activation between HSpp and PFpp cows, we performed a 2D-GE based proteome approach. Out of 1365 spots detected at the ap-fused image and out of the 1102 spots detected at the pp fused image, we picked only those spots whose expression differed between $\mathrm{P} 1$ and $\mathrm{P} 2$ by $P<0.1$ in HS but not in PF animals.

Out of 114 spots differentially expressed between P1 and P2 in HSap animals, and out of 82 spots differentially expressed between P1 and P2 in HSpp animals, we identified 18 spots for the ap and 20 spots for the pp period by mass spectrometry and data base search (Table 1). In the ap period, five enzymes involved in amino acid degradation, namely isovaleryl-CoA dehydrogenase (IVD), 3-hydroxyisobutyrate dehydrogenase (HIBADH), beta-ureidopropionase (UPB1), arginase-1 (ARG1) and glycine amidinotransferase (AGAT) were found to be 20-38\% lower expressed after heat challenge (Table 1 ). The proteasome subunit alpha (PSMA2), which is involved in protein degradation, coproporphyrinogen-III oxidase (CPOX), which is involved in haem biosynthesis, as well as ferritin light chain (FTL), the major iron storage protein, were all 1.4-2.7 fold upregulated, whereas 4-trimethylaminobutyraldehyde dehydrogenase (ALDH9A1), which is involved in carnitine biosynthesis, was 1.2-fold downregulated (Table 1). Among enzymes involved in carbohydrate and energy metabolism, UTP-glucose-1-phosphate uridylyltransferase (UGP1) was 1.3-fold upregulated, whereas galactokinase (GALK1), NADH-ubiquinone oxidoreductase (complex I), adenosine kinase (ADK) and carbonyl reductase 1 (CBR1) were 1.21.5-fold downregulated (Table 1). Furthermore, three spots coding for catalase (CAT) were all found 1.2-1.4 fold lower expressed after heat exposure (Table 1$)$.

In the pp period, we found the pyridoxal phosphatedependent enzyme serine hydroxymethyltransferase (SHMT) and three spots coding for 3-ketoacylCoA thiolase (ACAA2) 1.2-1.5 fold greater, but two http://joe.endocrinology-journals.org DOI: $10.1530 / J O E-17-0066$
(C) 2017 The authors Printed in Great Britain
Published by Bioscientifica Ltd 
Table 1 Quantity of liver protein spots differentially expressed between the P1 and P2 period of ante-partum and post-partum heat-stressed but not pair-fed cows.

\begin{tabular}{|c|c|c|c|c|c|c|c|}
\hline Stage & Gel spot No. & Description & Gene name & $\begin{array}{l}\text { Mean rel. } \\
\text { abundance } \\
\text { in P1 (Vol\%) }\end{array}$ & $\begin{array}{l}\text { Mean rel. } \\
\text { abundance } \\
\text { in } \mathbf{P 2}(\mathrm{Vol} \%)\end{array}$ & $\begin{array}{l}\text { Ratio } \\
\text { P2/P1 }\end{array}$ & $P$ value \\
\hline \multirow[t]{18}{*}{$\overline{\text { Ante-partum }}$} & 588 & Arginase-1 & ARG1 & 0.094 & 0.065 & 0.69 & 0.031 \\
\hline & 524 & Isovaleryl-CoA dehydrogenase & IVD & 0.039 & 0.025 & 0.62 & 0.094 \\
\hline & 782 & 3-Hydroxyisobutyrate dehydrogenase & HIBADH & 0.061 & 0.048 & 0.79 & 0.031 \\
\hline & 492 & Glycine amidinotransferase & AGAT & 0.303 & 0.243 & 0.80 & 0.031 \\
\hline & 528 & Beta-ureidopropionase & UPB 1 & 0.087 & 0.063 & 0.72 & 0.031 \\
\hline & 786 & Proteasome subunit alpha & PSMA2 & 0.008 & 0.021 & 2.67 & 0.031 \\
\hline & 628 & Coproporphyrinogen-III oxidase & CPOX & 0.015 & 0.029 & 1.99 & 0.063 \\
\hline & 995 & Ferritin light chain & FTL & 0.038 & 0.054 & 1.41 & 0.031 \\
\hline & 1339 & 4-Trimethylamino-butyraldehyde dehydrogenase & ALDH9A1 & 0.160 & 0.134 & 0.84 & 0.063 \\
\hline & 423 & UTP-glucose-1-phosphate uridylyltransferase & UGP1 & 0.200 & 0.262 & 1.31 & 0.031 \\
\hline & 639 & Galactokinase & GALK1 & 0.102 & 0.078 & 0.77 & 0.063 \\
\hline & 736 & Galactokinase & GALK1 & 0.046 & 0.036 & 0.78 & 0.063 \\
\hline & 241 & NADH-ubiquinone oxidoreductase, complex 1 & - & 0.029 & 0.020 & 0.67 & 0.063 \\
\hline & 1345 & Adenosine kinase & ADK & 0.207 & 0.179 & 0.86 & 0.031 \\
\hline & 768 & Carbonyl reductase 1 & CBR1 & 0.100 & 0.081 & 0.81 & 0.063 \\
\hline & 377 & Catalase & CAT & 0.593 & 0.480 & 0.81 & 0.063 \\
\hline & 1350 & Catalase & CAT & 0.300 & 0.234 & 0.78 & 0.031 \\
\hline & 574 & Catalase & CAT & 0.288 & 0.203 & 0.70 & 0.031 \\
\hline \multirow[t]{20}{*}{ Post-partum } & 199 & 3-Ketoacyl-CoA thiolase & ACAA2 & 0.202 & 0.311 & 1.54 & 0.063 \\
\hline & 207 & 3-Ketoacyl-CoA thiolase & ACAA2 & 0.058 & 0.114 & 1.21 & 0.063 \\
\hline & 327 & 3-Ketoacyl-CoA thiolase & ACAA2 & 0.081 & 0.121 & 1.51 & 0.063 \\
\hline & 1004 & Acetyl-coenzyme $A$ acetyltransferase 2 & ACAT2 & 0.125 & 0.092 & 0.73 & 0.063 \\
\hline & 1005 & Acetyl-coenzyme $A$ acetyltransferase 2 & ACAT2 & 0.108 & 0.063 & 0.58 & 0.063 \\
\hline & 1022 & Glycerol-3-phosphate dehydrogenase & GPDH & 0.109 & 0.075 & 0.68 & 0.063 \\
\hline & 183 & Serine hydroxymethyltransferase & SHMT & 0.059 & 0.120 & 1.26 & 0.063 \\
\hline & 170 & UTP-glucose-1-phosphate uridylyltransferase & UGP1 & 0.269 & 0.433 & 1.61 & 0.063 \\
\hline & 191 & Pyruvate carboxylase & PC & 0.002 & 0.020 & 1.32 & 0.063 \\
\hline & 194 & Fumarate hydratase & $\mathrm{FH}$ & 0.054 & 0.083 & 1.55 & 0.063 \\
\hline & 315 & Carbonyl reductase 1 & CBR1 & 0.318 & 0.631 & 1.98 & 0.063 \\
\hline & 862 & Regucalcin isoform $\times 1$ & REG1 & 1.137 & 0.910 & 0.80 & 0.063 \\
\hline & 893 & Sorbitol dehydrogenase & $\mathrm{SDH}$ & 0.235 & 0.190 & 0.81 & 0.063 \\
\hline & 663 & Profilin 1 & PFN1 & 0.039 & 0.037 & 0.96 & 0.063 \\
\hline & 937 & Protein disulfide-isomerase $\mathrm{A} 3$ & PDIA3 & 0.331 & 0.218 & 0.66 & 0.063 \\
\hline & 380 & Peroxiredoxin 6 & PRDX6 & 0.079 & 0.056 & 0.71 & 0.063 \\
\hline & 400 & Thioredoxin-dependent peroxide reductase & PRDX3 & 0.181 & 0.077 & 0.42 & 0.063 \\
\hline & 890 & Thiosulfate sulfurtransferase & TST & 0.249 & 0.194 & 0.78 & 0.063 \\
\hline & 934 & Catalase & CAT & 0.028 & 0.021 & 0.75 & 0.063 \\
\hline & 1066 & Persulfide dioxygenase & ETHE1 & 0.062 & 0.030 & 0.48 & 0.063 \\
\hline
\end{tabular}

acetyl-CoA acetyltransferase (ACAT2) spots and one GPDH spot 1.3-1.7-fold lower expressed after HS challenge (Table 1). Enzymes involved in glucose and energy metabolism were UGP1, pyruvate carboxylase (PC), fumarate hydratase (FH) and CBR1 which were 1.3-2-fold upregulated, while regucalcin 1 (RGN1) and sorbitol dehydrogenase (SDH) were 1.2-1.5-fold downregulated (Table 1). Profilin 1 (PFN1), which regulates actin polymerization, protein disulfideisomerase A3 (PDIA3), but also enzymes involved in the xenobiotic and oxidative stress defense machinery, namely thiosulfate sulfurtransferase (TST), thioredoxindependent peroxide reductase (PRDX3), peroxiredoxin 6
(PRDX6), CAT and persulfide dioxygenase (ETHE1) were downregulated after HS challenge (Table 1).

Next, we examined whether changes in regucalcin (spot 862) and protein disulfide-isomerase (spot 937) abundances can be verified by Western blot analysis. After heat exposure, regucalcin abundance was found significantly lower than in the preceding period P1 (Fig. 3A). By using an antibody directed against protein disulfide-isomerase precursor protein (P4HB) (Fig. 3B), we could not confirm changes in PDIA3 abundance as identified by the proteome approach (Table 1). Also, the secondary $\mathrm{T}_{3}$ marker gene ATP5B was not regulated on the protein level in response to heat stress or pair-feeding in http://joe.endocrinology-journals.org DOI: 10.1530/JOE-17-0066 (c) 2017 The authors Printed in Great Britain
Published by Bioscientifica Ltd. 

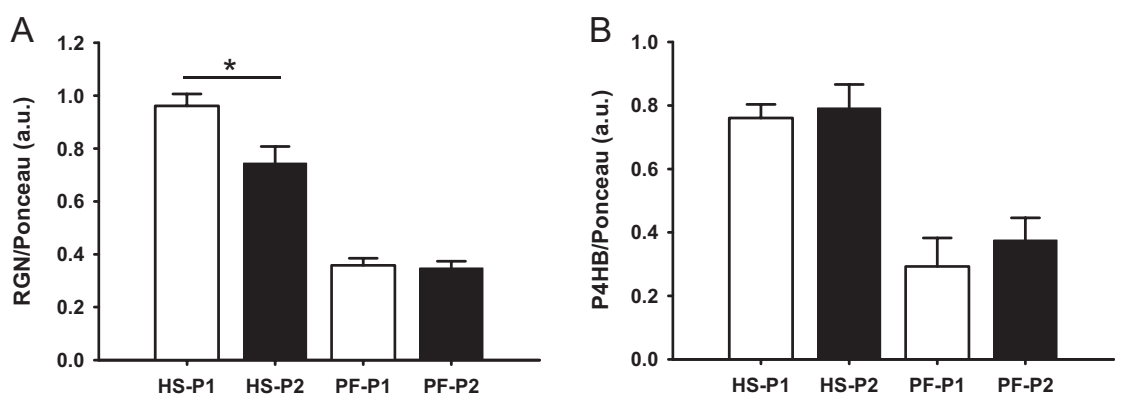

Figure 3

Western blot analysis of regucalcin (RGN) (A), protein disulfide-isomerase precursor (P4HB) (B) and ATP synthase subunit beta (ATP5B) (C),
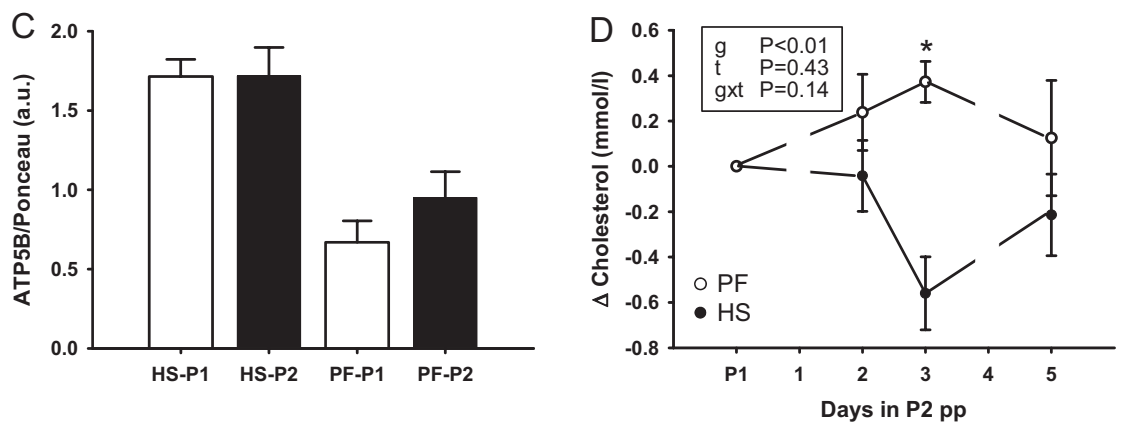
relative to Ponceau staining. Liver samples were obtained after ad libitum feeding at thermoneutrality (P1; open bars) and after heat stress (HS; filled bars) or pair-feeding at thermoneutrality (PF; filled bars) at day 7 in P2 of the post-partum period. Baseline-corrected plasma cholesterol concentrations obtained after ad libitum feeding in P1 and during HS (filled circles) or PF (open circles) in P2 of the postpartum period (D). Data are from HSpp $n=6$, PFpp $n=4$ and are presented as mean \pm S.E.M. * indicates $P<0.05$.

the pp period (Fig. 3C). Further, as ACAT2 is known to be involved in many metabolic pathways, among them in hepatic acetoacetyl-CoA and cholesterol synthesis, we examined whether the decrease in ACAT2 in response to HS would be associated with declining plasma cholesterol concentrations. Exposure to HS leads to significantly lower plasma cholesterol concentrations compared to PF on day 3 of challenge but not on day 7 of the pp challenge (Fig. 3D).

\section{Discussion}

Food restriction in dairy cows either in the ap or pp stage leads to a decrease in triiodothyronine and thyroxine concentrations by $40-47 \%$ after a 7 -day challenge. This has been expected as essential in order to ensure the demand for a reduced metabolic rate and to confine increase in body temperature in these animals (McGuire et al. 1991, West 2003, Lamp et al. 2015). Heat-stressed animals kept at $28^{\circ} \mathrm{C}(\mathrm{THI}=76)$ respond with an even more pronounced decline in $\mathrm{T}_{3}$ and $\mathrm{T}_{4}$ levels (Fig. 1), and the extent of reduction was more prominent in $\mathrm{HS}$ compared to $\mathrm{PF}$ animals in the ap state and tended to be different for total plasma $\mathrm{T}_{4}$ concentrations in the pp period. This again is in agreement to previous data observed in beef cattle as well as in lactating cows (Magdub et al. 1982, Al-Haidary et al. 2001). However, the major contributor of declining $\mathrm{TH}$ concentrations is the reduction in feed intake, while HS adds only a minor portion to the reduction. TSH levels remain constant over the observation period both in the PF as well as in the HS group (Fig. 1C and F). This is contradicting to a previous report by Kahl et al. (2015) in which the authors describe reduced TSH levels in heatstressed steers. Differences in the experimental setting, between breeds, gender and physiological status may account for these diverse observations. More specifically, in the study by Kahl et al. (Kahl et al. 2015) male animals have been observed, whereas we herein investigated female animals three weeks before or three weeks after parturition. Further, heat stress has been induced in a daily cycling manner, whereas we used a constant temperature regime. A constant TSH level, as observed in our study, indicates that $\mathrm{TH}$ levels are tailored to meet the requirement in our experimental design over the observation period.

In a next step, we investigated hepatic marker genes which are essential for thyroid hormone-dependent gene regulation in liver. After binding of TH to THR these liganded nuclear receptors regulate a series of primary $\mathrm{TH}$ target genes via direct binding to $\mathrm{TH}$ response elements in the promoter region of these target genes ('early' gene regulation). The un-liganded THR regulates gene transcription in an opposite manner, and additionally many non-genomic actions of $\mathrm{TH}$ have been described which further fine tune the action of the hormone in different tissues (Cheng et al. 2010, Astapova \& Hollenberg 2013, Cioffi et al. 2013, Davis et al. 2013). Among the primary THR target genes, the transcription factor NRF1, the transcriptional coactivator PPARGC1 and http://joe.endocrinology-journals.org DOI: 10.1530/JOE-17-0066
(C) 2017 The authors Printed in Great Britain
Published by Bioscientifica Ltd. 
the TH converting enzyme DIO1 have been described to be directly regulated via a $\mathrm{TH}$ response element (Jakobs et al. 1997, Wulf et al. 2008). Both, NRF1 and PPARGC1 genes are cooperatively involved in regulating mitochondrial biogenesis in the liver (Weitzel \& Iwen 2011), whereas the main activity of DIO1 is to convert $\mathrm{T}_{4}$ into the biologically more potent $\mathrm{T}_{3}$ (Gereben et al. 2015). All these target genes are positively regulated upon $\mathrm{T}_{3}$ stimulus and regulate specific key steps in TH action in the liver. Interestingly, these marker genes responded differentially in the ap and pp period (Fig. 2). In the ap state, the abundance of marker genes did not change when cows were transferred from thermoneutrality to heat and only DIO1 differed between HS and PF cows, although total $\mathrm{T}_{3}$ and $\mathrm{T}_{4}$ plasma concentrations declined even more in HS than PF animals. By contrast, in the pp state, we found significantly reduced THRA, DIO1 and PPARGC1A transcript levels, both by comparing HS to ad libitum fed (HS-P1) and by comparing HS-P2 to PF-P2 cows, but these changes were not associated with different $T_{3}$ and $T_{4}$ plasma concentrations, at least not on day 7 of challenge. These results indicate that TH-mediated signaling in early lactation but not in late pregnancy is specifically regulated due to increased temperature but not due to accompanied reduced energy intake. Our results further demonstrate diminished hepatic TH sensitivity in HS late pregnant cows. The non-responsiveness of TH-mediated signaling in HS late pregnant cows may be due to the level of total plasma $T_{4}$, which was generally greater in the ap compared to the pp period, both in the basal state P1 as well as after challenge. However, the post-partum mitochondrial activity regulated by the transcription factor-coactivator complexes THRA/PPARGC1A and/ or NRF1/PPARGC1A during HS seems to be dampened and might account for the switch from fat to glucose utilization as observed previously (Eslamizad et al. 2015). Interestingly, a decline of DIO1 enzyme activity has also been described in the above-mentioned study by Kahl and coworkers (Kahl et al. 2015). By contrast, we did not find a significant alteration in steady-state protein concentrations of ATP5B (Fig. 3C) as well as not for protein disulfide-isomerase precursor (P4HB) (Fig. 3B). Although ATP5B is known as a secondary TH target, a direct regulation via a $\mathrm{TH}$ response element has not been described for both genes. Indeed, hormone-mediated alterations of ATP5B and P4HB gene transcription have been described with a delay of $72 \mathrm{~h}$ which is followed by an alteration of protein concentrations earliest detectable 4-5 days after TH stimulus (Obata et al. 1988,
Weitzel \& Iwen 2011). Possibly, the treatment time of only 7 days (including one day of thermal transition) in our experimental setting might be too short in order to induce manifest expression alterations. In addition, in post-partum PF cows, the abundance of THRA, NRF1, DIO1 and PPARGC1A was greater than in HS cows, a regulation which might help to switch hepatic metabolism toward fatty acid oxidation during times of energy deficiency at thermoneutrality.

A switch of metabolic rate and a switch in substrate oxidation from thermoneutrality to heat exposure as discussed above and described earlier (Lamp et al. 2015) are also evident from our proteomics approach. Of note, we only analyzed those protein spots which were (i) differentially expressed between P1 and P2 of HS cows while (ii) remaining unaffected in PF cows. Thus, differential protein abundances listed in Table 1 can be specifically attributed to heat stress but not to reduced energy intake.

Several enzymes related to fat metabolism were found differentially expressed after heat exposure in the pp but not ap period. The ACAA2 protein was upregulated as compared to thermoneutral conditions, suggesting activated hepatic beta-oxidation. This finding seems to contradict earlier results demonstrating that lactating dairy cows are refractory to lipolysis and accordingly do not increase whole-body fat oxidation when adapting to ambient heat (Lamp et al. 2015), but the latter does not exclude that fatty acid oxidation may be activated in other organs. On the mRNA transcript level, hepatic mitochondrial beta-oxidation enzymes were not affected when cows in early lactation were heat stressed (Koch et al. 2016). As gene transcription costs up to $10 \%$ of the total cellular energy, oligonucleotide synthesis is often suppressed to confine endogenous heat production (Storey 2015). Thus, other mechanisms, primarily epigenetic and post-translational protein modifications gain importance in the control of enzyme activities during hypometabolism (Storey 2015), but whether the protein spots identified as ACAA2 were post-translationally modified need to be determined in future studies. Upregulation of UGP1, an enzyme involved in glycosylation of proteins, points to activated post-translation both in the ap and pp stage, which supports our assumption above. However, increased hepatic fatty acid oxidation during pp heat stress should generate substantial amounts of NADH, which in turn serve as substrate for an activated gluconeogenic pathway (see below). A further link between carbohydrate and lipid metabolism is controlled by GPDH. GPDH catalyzes http://joe.endocrinology-journals.org DOI: $10.1530 / \mathrm{JOE}-17-0066$
(C) 2017 The authors Printed in Great Britain
Published by Bioscientifica Ltd 
the reversible reduction of dihydroxyacetone phosphate into glycerol 3-phosphate and finally glycerol and serves as a regulator controlling the provision of electrons to the electron transport chain in the mitochondria. Thus, reduced abundance of GPDH during pp heat stress indicates reduced hepatic lipid biosynthesis and a reduced electron flux through the respiratory chain, thereby reducing endogenous heat production while maintaining electron provision for gluconeogenesis. In addition, ACAT2, an enzyme involved in ketone body and cholesterol production, was lower expressed after the pp heat stress challenge, explaining sustained plasma beta-hydroxybutyrate concentrations in HS while they increased in PF early lactating cows (Koch et al. 2016). Further, downregulation of ACAT2 agrees to the declining plasma cholesterol concentrations of HS cows post-partum.

The hepatic amino acid catabolism was found differently regulated in the ap and pp period. While the amino acid catabolism is reduced after heat stress in late pregnant cows, it is activated in heat-stressed early lactating cows. The reduced expression of IVD, HIBADH, UPB1, and ARG1 in heat-stressed late pregnant cows together with increased expression of PSMA2 indicates intensified hepatic protein degradation but diminished branched-chain amino acids catabolism, likely because to direct these amino acids to the rapidly growing fetus. These data agree to a recent finding demonstrating that plasma urea concentrations do not increase after heat stress of pregnant cows (Koch et al. 2016). As a consequence of the reduced amino acid catabolism, mitochondrial energy production should also be reduced and accordingly complex I, ADK1 and CBR1 were lower expressed in late pregnant cows after heat exposure. On the contrary, upregulation of SHMT and ACAT2 proteins post-partum points to a stimulated hepatic amino acid catabolism aligned with significantly increased plasma urea concentrations described for HS but not PF lactating cows (Koch et al. 2016), probably because there is no need any more to transfer amino acids to the fetus. Instead, amino acids can be catabolized to produce energy leading inevitably to an increased urea cycling. Although we did not observe upregulation of urea cycle enzymes either at protein or at transcriptional level (Koch et al. 2016), the carbon chain of amino acids entered the TCA cycle and accordingly we found increased abundance of FH protein after heat exposure. Fumarate is converted to malate and the latter further to oxaloacetate, the main precursor for gluconeogenesis. In the present study, we found increased abundance of PC protein during pp heat stress, suggesting activated gluconeogenesis. In line with this, Shahzad et al. (Shahzad et al. 2015) reported a greater PC mRNA abundance in transition cows with summer compared to winter calving, although this might be due to the lower feed intake as well. However, lactating cows adapt to heat by increasing carbohydrate utilization (Rhoads et al. 2009, Lamp et al. 2015), and increased gluconeogenesis may meet these increased glucose requirements.

It has been shown that administration of $\mathrm{T}_{3}$ results in transcriptional upregulation of enzymes with oxidative stress defense characteristics such as superoxide dismutase (SOD) and CAT (Weitzel et al. 2001, 2003). Vice versa, reduction in plasma $\mathrm{T}_{3}$ concentration in HSap animals is accompanied by a reduction of the stress defense enzyme CAT, and thus corresponds to the declined hepatic mRNA abundance of CAT after heat exposure of early lactating dairy cows (Koch et al. 2016). Moreover, the trend in declining plasma $\mathrm{T}_{3}$ concentration in HSpp animals is associated by reduction of the stress defense enzymes TST, PRDX3, PRDX6, ETHE1 and also CAT, strongly suggesting the involvement of $\mathrm{T}_{3^{-}}$and THRA-mediated signaling in this adaptation process. Downregulation of these defense enzymes seems to be a mechanism to allow for accumulating levels of peroxides and other reactive oxygen species, which in turn may activate transcription factors such as heat shock factor 1 (HSF1) or hypoxia-inducible factor 1 (HIF1), both known to trigger cellular heat stress responses (Klumpen et al. 2017).

Taken together, our data indicate that Holstein cows responded with a decline in $\mathrm{T}_{3}$ and $\mathrm{T}_{4}$ to ambient heat or pair-feeding, but the extent of the decline was greater under heat-stressed conditions, particularly in the ap and as a trend in the pp period. However, absolute plasma $T_{4}$ concentrations reached lower levels pp than ap. Hepatic marker genes of $\mathrm{TH}$ action did not respond in late pregnant cows indicating reduced TH sensitivity, likely to confine amino acid catabolism in order to direct amino acids to the fetus. On the other hand, hepatic mRNA abundances of THRA, DIO1, NRF1 and PPARGC1 were lower in HS than PF challenged early lactating cows, thus allowing TH-signal transduction to facilitate amino and fatty acid catabolism as well as gluconeogenesis during heat stress. However, activation of these metabolic pathways during heat stress is accompanied by diminished oxidative defense in early lactating cows. http://joe.endocrinology-journals.org

DOI: $10.1530 / \mathrm{JOE}-17-0066$
(C) 2017 The authors Printed in Great Britain
Published by Bioscientifica Ltd 


\section{Supplementary data}

This is linked to the online version of the paper at http://dx.doi.org/10.1530/ JOE-17-0066.

\section{Declaration of interest}

The authors declare that there is no conflict of interest that could be perceived as prejudicing the impartiality of the research reported.

\section{Funding}

This study was supported by the core budged of the Leibniz Institute for Farm Animal Biology (FBN). This research did not receive any grant from the commercial sector.

\section{Acknowledgements}

We thank M Althaus, S Wiese, C Arlt and the staff at the FBN cattle facility and the 'Tiertechnikum' for help with biochemical analyses and animal care.

\section{References}

Al-Haidary A, Spiers DE, Rottinghaus GE, Garner GB \& Ellersieck MR 2001 Thermoregulatory ability of beef heifers following intake of endophyte-infected tall fescue during controlled heat challenge. Journal of Animal Science 79 1780-1788. (doi:10.2527/2001.7971780x)

Astapova I \& Hollenberg AN 2013 The in vivo role of nuclear receptor corepressors in thyroid hormone action. Biochimica et Biophysica Acta 1830 3876-3881. (doi:10.1016/j.bbagen.2012.07.001)

Basirico L, Morera P, Primi V, Lacetera N, Nardone A \& Bernabucci U 2011 Cellular thermotolerance is associated with heat shock protein 70.1 genetic polymorphisms in Holstein lactating cows. Cell Stress and Chaperones 16 441-448. (doi:10.1007/s12192-011-0257-7)

Cheng SY, Leonard JL \& Davis PJ 2010 Molecular aspects of thyroid hormone actions. Endocrine Reviews 31 139-170. (doi:10.1210/ er.2009-0007)

Cioffi F, Senese R, Lanni A \& Goglia F 2013 Thyroid hormones and mitochondria: with a brief look at derivatives and analogues. Molecular and Cellular Endocrinology 379 51-61. (doi:10.1016/j. mce.2013.06.006)

Davis PJ, Lin HY, Tang HY, Davis FB \& Mousa SA 2013 Adjunctive input to the nuclear thyroid hormone receptor from the cell surface receptor for the hormone. Thyroid 23 1503-1509. (doi:10.1089/ thy.2013.0280)

Eslamizad M, Lamp O, Derno M \& Kuhla B 2015 The control of shortterm feed intake by metabolic oxidation in late-pregnant and early lactating dairy cows exposed to high ambient temperatures. Physiological Behavior 145 64-70. (doi:10.1016/j.physbeh.2015.03.044)

Eto K, Tsubamoto Y, Terauchi Y, Sugiyama T, Kishimoto T, Takahashi N, Yamauchi N, Kubota N, Murayama S, Aizawa T, et al. 1999 Role of NADH shuttle system in glucose-induced activation of mitochondrial metabolism and insulin secretion. Science 283 981-985. (doi:10.1126/ science.283.5404.981)

Gereben B, McAninch EA, Ribeiro MO \& Bianco AC 2015 Scope and limitations of iodothyronine deiodinases in hypothyroidism. Nature Reviews Endocrinology 11 642-652. (doi:10.1038/nrendo.2015.155)

Jakobs TC, Schmutzler C, Meissner J \& Kohrle J 1997 The promoter of the human type I 5 -deiodinase gene - mapping of the transcription start site and identification of a DR+4 thyroid-hormone-responsive element. European Journal of Biochemistry 247 288-297. (doi:10.1111/ j.1432-1033.1997.00288.x)

Kahl S, Elsasser TH, Rhoads RP, Collier RJ \& Baumgard LH 2015 Environmental heat stress modulates thyroid status and its response to repeated endotoxin challenge in steers. Domestic Animal Endocrinology 52 43-50. (doi:10.1016/j.domaniend.2015.02.001)

Klumpen E, Hoffschroer N, Zeis B, Gigengack U, Dohmen E \& Paul RJ 2017 Reactive oxygen species (ROS) and the heat stress response of Daphnia pulex: ROS-mediated activation of hypoxia-inducible factor 1 (HIF-1) and heat shock factor 1 (HSF-1) and the clustered expression of stress genes. Biology of the Cell 109 39-64. (doi:10.1111/ boc. 201600017)

Koch F, Lamp O, Eslamizad M, Weitzel J \& Kuhla B 2016 Metabolic response to heat stress in late-pregnant and early lactation dairy cows: implications to liver-muscle crosstalk. PLOS ONE 11 e0160912. (doi:10.1371/journal.pone.0160912)

Lamp O, Derno M, Otten W, Mielenz M, Nurnberg G \& Kuhla B 2015 Metabolic heat stress adaption in transition cows: differences in macronutrient oxidation between late-gestating and early-lactating german holstein dairy cows. PLoS ONE 10 e0125264. (doi:10.1371/ journal.pone.0125264)

Magdub A, Johnson HD \& Belyea RL 1982 Effect of environmental heat and dietary fiber on thyroid physiology of lactating cows. Journal of Dairy Science 65 2323-2331. (doi:10.3168/jds.S0022-0302(82)82504-6)

McGuire MA, Beede DK, Collier RJ, Buonomo FC, DeLorenzo MA, Wilcox CJ, Huntington GB \& Reynolds CK 1991 Effects of acute thermal stress and amount of feed intake on concentrations of somatotropin, insulin-like growth factor (IGF)-I and IGF-II, and thyroid hormones in plasma of lactating Holstein cows. Journal of Animal Science 69 2050-2056. (doi:10.2527/1991.6952050x)

Meyerholz MM, Mense K, Linden M, Raliou M, Sandra O, Schuberth HJ, Hoedemaker M \& Schmicke M 2016 Peripheral thyroid hormone levels and hepatic thyroid hormone deiodinase gene expression in dairy heifers on the day of ovulation and during the early peri-implantation period. Acta Veterinaria Scandinavica 5852. (doi:10.1186/s13028-016-0231-6)

Mullur R, Liu YY \& Brent GA 2014 Thyroid hormone regulation of metabolism. Physiological Reviews 94 355-382. (doi:10.1152/ physrev.00030.2013)

NRC 1971 A guide to environmental research on animals. Committee on Physiological Effects on Environmental factors on Aminlas AB, National Research Council 374.

Obata T, Kitagawa S, Gong QH, Pastan I \& Cheng SY 1988 Thyroid hormone down-regulates $\mathrm{p} 55$, a thyroid hormone-binding protein that is homologous to protein disulfide isomerase and the betasubunit of prolyl-4-hydroxylase. Journal of Biological Chemistry 263 782-785.

Piehl S, Hoefig CS, Scanlan TS \& Kohrle J 2011 Thyronamines - past, present, and future. Endocrine Reviews 32 64-80. (doi:10.1210/er.20090040)

Rhoads ML, Rhoads RP, Vanbaale MJ, Collier RJ, Sanders SR, Weber WJ, Crooker BA \& Baumgard LH 2009 Effects of heat stress and plane of nutrition on lactating Holstein cows: I. Production, metabolism, and aspects of circulating somatotropin. Journal of Dairy Science $\mathbf{9 2}$ 1986-1997. (doi:10.3168/jds.2008-1641)

Schaff C, Borner S, Hacke S, Kautzsch U, Albrecht D, Hammon HM, Rontgen M \& Kuhla B 2012 Increased anaplerosis, TCA cycling, and oxidative phosphorylation in the liver of dairy cows with intensive body fat mobilization during early lactation. Journal of Proteome Research 11 5503-5514. (doi:10.1021/pr300732n)

Shahzad K, Akbar H, Vailati-Riboni M, Basirico L, Morera P, Rodriguez-Zas SL, Nardone A, Bernabucci U \& Loor JJ 2015 The effect of calving in the summer on the hepatic transcriptome of Holstein cows during the peripartal period. Journal of Dairy Science 98 5401-5413. (doi:10.3168/ jds.2015-9409) 
Storey KB 2015 Regulation of hypometabolism: insights into epigenetic controls. Journal of Experimental Biology 218 150-159. (doi:10.1242/ jeb.106369)

Vicari T, van den Borne JJ, Gerrits WJ, Zbinden Y \& Blum JW 2008 Postprandial blood hormone and metabolite concentrations influenced by feeding frequency and feeding level in veal calves. Domestic Animal Endocrinology 34 74-88. (doi:10.1016/j. domaniend.2006.11.002)

Warner A, Rahman A, Solsjo P, Gottschling K, Davis B, Vennstrom B, Arner A \& Mittag J 2013 Inappropriate heat dissipation ignites brown fat thermogenesis in mice with a mutant thyroid hormone receptor alpha1. PNAS 110 16241-16246. (doi:10.1073/pnas.1310300110)

Weitzel JM \& Iwen KA 2011 Coordination of mitochondrial biogenesis by thyroid hormone. Molecular and Cellular Endocrinology 342 1-7. (doi:10.1016/j.mce.2011.05.009)

Weitzel JM, Radtke C \& Seitz HJ 2001 Two thyroid hormone-mediated gene expression patterns in vivo identified by cDNA expression arrays in rat. Nucleic Acids Research 29 5148-5155. (doi:10.1093/ nar/29.24.5148)

Weitzel JM, Hamann S, Jauk M, Lacey M, Filbry A, Radtke C, Iwen KA, Kutz S, Harneit A, Lizardi PM, et al. 2003 Hepatic gene expression patterns in thyroid hormone-treated hypothyroid rats. Journal of Molecular Endocrinology 31 291-303. (doi:10.1677/jme.0.0310291)

West JW 2003 Effects of heat-stress on production in dairy cattle. Journal of Dairy Science 86 2131-2144. (doi:10.3168/jds.S00220302(03)73803-X)

Wheelock JB, Rhoads RP, Vanbaale MJ, Sanders SR \& Baumgard LH 2010 Effects of heat stress on energetic metabolism in lactating Holstein cows. Journal of Dairy Science 93 644-655. (doi:10.3168/jds.2009. 2295)

Wulf A, Harneit A, Kroger M, Kebenko M, Wetzel MG \& Weitzel JM 2008 T3-mediated expression of PGC-1alpha via a far upstream located thyroid hormone response element. Molecular and Cellular Endocrinology 287 90-95. (doi:10.1016/j.mce.2008.01.017)

Received in final form 5 May 2017

Accepted 11 May 2017

Accepted Preprint published online 12 May 2017 (c) 2017 The authors Printed in Great Britain
Published by Bioscientifica Ltd. 